\title{
Notas sobre Andrés Bello y América Latina
}

\section{AL MOMENTO DE LAS PRIMERAS PREGUNTAS}

Sabemos que es una virtud de la edad madura de las naciones, pensarse a sí mismas. Difícilmente sin un ejercicio dilatado de vida puede un pueblo "preocuparse" por desentrañar sus esencias o, al menos, sus particularidades más íntimas, que sólo serán aquellas más permanentes. En este aspecto, los países recién independizados de Hispanoamérica, fueron precoces ante la urgencia de elegir un "proyecto civilizador" determinado. Sabemos, también, quiénes fueron los "adelantados" del pensamiento latinoamericano.

Cada nación en esta área del mundo venera o vitupera (o ambas cosas) a sus "prohombres" del intelecto inicial. Hablando de este tópico, dice el novelista y ensayista argentino Ernesto Sábato que: "frente a la de Sarmiento, hay otra presencia magnífica, la de BeIlo, hombre que había estudiado filosofía y ciencias en Londres, sistemático y riguroso. Un creador que realizó una obra asombrosa, si se tiene en cuenta el medio en que le tocó actuar, hasta el punto de que uno se pregunta lo que podría haber dado su genio de no haber venido - de pura generosidad y patriotismo- a estas tierras terribles, en que muchas veces hubo que hacer la patria con un libro en una mano y una espada en la otra.

"Y así sacrificó su calidad de "scholar" a las modestas pero insoslayables faenas de construir una patria. Porque para aquellos espíritus superiores, era la Magna Patria y no estas desunidas provincias"1.

Al otro extremo de esta región, el filósofo mexicano Leopoldo Zea nos dice que la preocupación por hacer Latinoamérica empezó en las inquietudes de Andrés Bello, pasando por Lastarria, Sarmiento, Alberdi, Mora, Luz y Caballero, Montalyo y otros: "fueron estos pensadores los que empezaron a hacerse preguntas. Algo tenía

1Ernesto Sábato: "Los libros y su misión en la liberación e integración de América Latina". Publicaciones de la Embajada de Venezuela en Buenos Aires. 1978 , p. 32. 
que ser América Latina, sus pueblos y sus hombres. Algo habría que los definiese como tales; y este algo podría ser el punto de partida para la realización de lo que anhelaban ser". Añ̃ade Zea que: "no podían actuar dentro de un vacío de pasado, que no se acepta$\mathrm{ba}$; y frente a un vacío de futuro por lo que no era o no podía ser"2. Pero los "prohombres" mencionados no eran, necesariamente, del mismo parecer. Sólo compartían la inquietud. Producido el hecho de la independencia política, había que desarrollar la libertad y enhebrar una nueva convivencia social. Todo ello suponía un "proyecto civilizador" que sirviera de marco. De Sarmiento o de Lastarria, por ejemplo, no hubiera podido decir Sábato que eran "sistemáticos y rigurosos". Eran, al fin y al cabo, románticos y apasionados. La imaginación les desbordaba un rigor entendido científicamente. No pretendemos con ello "jerarquizar" cualidades que no son opuestas, sino destacar el contraste anímico que les hacía proponer (o promover) distintos "proyectos civilizadores" para la incipiente región. Hay en Sarmiento, Lastarria, Mora, y mucho menos en Alberdi, por citar algunos, un efecto de "deslumbramiento" por la cultura europea, un positivismo (o "voluntarismo") que les encandila la dura y áspera realidad latinoamericana. ICivilización o barbariel... Copiando Europa, seríamos como ellos ... Había que "demoler" la realidad latinoamericana y empezar a construir con los aportes exclusivos de Estados Unidos, Francia o Gran Bretaña. España, a su manera, era "bárbara". Frente a ese planteamiento, a aquella "alienación", es que el pensamiento de Bello resultaba "sabio". Es curioso que el máximo calificativo que pueda recibir el intelecto humano sea la palabra aquella, que deriva de "saber". Cuando la verdad es que sin "comprender" no puede haber sabiduría. Sabio es simplemente el que comprende bien, aunque no sepa mucho. El pensamiento de Bello en relación a su proyecto cultura para la Hispanoamérica de su época ha sido tildado de "conservador". En cambio, los ideólogos de la familia de Sarmiento, con todos los matices y variaciones del caso, serían los liberales, o más propiamente, los "libertarios".

No parecen propios los calificativos aquellos, por la posibilidad de que se crea que Bello era "estático", maniatado por el pasado, condicionado, o que no era también libertario. Se podría más bien elegir calificativos que recalcaran el "realismo" frente al "embrujo".

Es obvio que los "prohombres" del pensamiento latinoamericano fueron contemporáneos de la Colonia, con todas sus instituciones y realidades. Aquella era su "circunstancia".

Dice el historiador chileno Ricardo Krebs: "entre las distintas características de la historia debe destacarse el hecho de que la di-

2Leopoldo Zea: "América Latina y el mundo". Editorial Universitaria de Buenos Aires, 1965. pp. 8-9. 
mensión propia de ella es el tiempo. El tiempo histórico está sujeto a las categorías de continuidad y cambio. Si no hubiese continuidad, no habría historia, ya que todo seguiría siempre igual"3.

Por su parte, el sociólogo José Ingenieros, personalidad múltiple y. fecunda, escribe en su obra "La evolución de las ideas argentinas" que:

"toda transmutación histórica tiene tres fases: 1, Los ideales revolucionarios se postulan como doctrinas universales y obran con ese carácter mezclando lo posible con lo imposible. 2) Fracasan parcialmente por la resistencia que le oponen los intereses creados de las diversas realidades sociales, demostrando y eliminando lo imposible, aunque transitoriamente también se elimina lo posible: restauración. 3) Se establece el equilibrio, renunciando a lo imposible y realizando lo posible: organización".

En momento alguno postuló Bello "continuar" la Colonia, sino simplemente evitar las crisis que provocan los proyectos sin "memoria"' histórica.

Si se califica de "conservador" el planteamiento de Bello, imaginemos el de Vasconcelos o el de Haya de la Torre; reinvindicadores de las culturas del antiguo México o del Perú. X bien puede ser, por otra parte, que ciertas instituciones que regían la convivencia de la América Indígena -debidamente adaptadas- puedan servir para moldear la vida social en. algunos puntos determinados del ancho escenario americano. De hecho ello ocurre, como ya es tradición profuncla, a pesar de la norma escrita.

Imaginemos a Bello antes de llegar a "estas tierras terribles", estudiando a Bentham; conversando con Stuart Mill; preocupado de las crónicas históricas medievales y del Poema del Mio Cid; enseñando a la familia Hamilton; devorando, "sistemática y rigurosamente", los libros del Museo Británico. También representando a la manera quieta de la época, los intereses de las Legaciones de Chile o de Colombia, cuando los hubiere. Y así, desde 1810 a 1829. ¿Gómo hubiesen emergido de aquella experiencia individuos como Sarmiento o Lastarria? O, simplemente, cualquiera que no fuera él. A lo mejor, más "temperados". ¿ $\mathrm{O}$ cómo hubiera sido Bello gobernante? Si Andrés Bello; y al parecer pudo sucederle, regresa a Caracas y al poco tiempo asume funciones de poder, América Latina hubiera perdido un humanista y Venezuela adquirido un gobernante culto. La conjetura en la historia es un ejercicio estéril y pa-

'Krebs: "Un: proyecto de investigación de historia". Publicaciones pruc. 1980, p. 63. Universidad Católica de Santiago de Chile. 
rece sacrílega aplicada a aquel que Joaquín Edwards Bello llamó "el bisabuelo de piedra".

También Bello, antes de llegar, preparaba una "Biblioteca" y un "Repertorio" americanos. La diferencia más profunda de Andrés Bello con otros "prohombres", de la región, es que él nunca dejó de ser "criollo", aprendiendo $y$ enseñando. No fue a adquirir ideologías para derramarlas a su regreso como si fueran semillas de té o recetas infalibles de una determinada escuela filosófica o económica. Está clara la preferencia que le daba su mente a la "reflexión" sobre la "repetición", en el sistema de la enseñanza que llegó a implantar, adelantándose un siglo y medio a los métodos pedagógicos hoy parcialmente imperantes. También está claro que no sólo en aquella época iban y volvían nuestros estudiosos "embrujados" con los postulados filosóficos, políticos o económicos de moda. Los santuarios "cambian de lugar", pero los peregrinos continúan volviendo anonadados.

Difícilmente podríamos pedirle a Andrés Bello un cuerpo único de ideas sobre sus planteamientos culturales, políticos y jurídicos para ser aplicados en América Latina, o en un país determinado de la región. Sus inquietudes no eran como las de Alberdi, redactar "Bases" propias de una plataforma política. Andrés Bello debía ser ni más ni menos que el consultor pronto, docto y prudente que guiara, ilustrara e informara a la autoridad. A la vez que el "maestro" y el ensayista acucioso. Sus polémicas no podían pasar más allá de las cuestiones estéticas y así y todo, sin estridencia. Pero si la prudencia es la virtud de los sabios, es difícil imaginar que aqueIlos límites le estorbaban, aún en el alboroto del Chile de la época, con el cual terminara por consustanciarse. Por otra parte, dentro de la región no había mayores posibilidades de elección..

El doctor en Filosoffa y Letras, José Vila Selma, que es español, formula una buena pregunta en relación a Bello: ¿qué hubiere ocurrido si todos o gran parte de los países latinoamericanos hubieren contado con un intelectual semejante?5.

Ya nos pronunciamos contra la tentación de las conjeturas, pero como veremos más adelante, la posibilidad de un entendimiento entre nuestras naciones hubiese sido mayor; más nítidos los compromisos y más despejado el horizonte de paz, de progreso y de comercio. La influencia "sistemática y rigurosa" de un jurista de las dimensiones de Bello, tan cerca permanentemente de las autoridades, desprovisto de ambiciones políticas personales, era un foco que irradiaba prudencia y justicia.

'Ese es el título de un libro que contiene artículos del autor mencionado; editado por Nascimento, Santiago de Chile, 1978.

${ }^{5}$ Antología de Discursos y Escritos de Andrés Bello. Edición preparada por José Vila Selma. Editorial Nacional. Madrid. España, 1976. 
Así lo comprendieron, perfectamente bien, los gobernantes chilenos de la época. No está contradicha la afirmación de Feliú Gruz de que "Bello fue el mentor de la política internacional de Chile, desde el 15 de abril de 1830 hasta el 30 de junio de 1834, tiempo en el cual no pertenecía a la planta del Ministerio, o sea durante cuatro años; y desde esa última fecha, hasta diciembre de 1853, durante dieciocho años. En total, Bello dirigió las relaciones exteriores de Chile en un espacio de veintidós años".

Barros Arana, a su vez, interpreta cabalmente las ideas de Irisarri, Federico Errázuriz, Miguel Luis Amunátegui, Alberto Cruchaga Ossa y tantos otros, cuando escribe en "Un Decenio de la Historia de Chile" las siguientes expresiones:

"La República de Chile iba venciendo con rara felicidad todas las dificultades que embarazaban la organización interior, y había alcanzado a constituir un gobierno regular y ordenado bajo un régimen templado de moderación, de libertad y de aspiraciones a un legítimo progreso. Pcro tenía además que luchar con dificultades de orden diverso, provenientes de las relaciones con otros países, los cuales exigían, junto a una atención vigorosa y discreta, una sólida preparación intelectual. La República tuvo la fortuna de contar para este servicio con un hombre excepcional por su talento y por su saber, que desde el destino relativamente modesto de Subsecretario de Relaciones Exteriores, daba con gran acierto rumbo y carácter a los negocios que estaban a su cargo. ¿Necesitamos decir que hablamos de don Andrés Bello?"'.

Llama la atención en el extranjero que cuando se quiere configurar el pensamiento político de Andrés Bello, se recurra a altos documentos oficiales de la época; a discursos presidenciales en la inauguración de las Legislaturas entre 1831 y 1860; a documentos internacionales y administrativos que van desde 1831 a 1852 y no soIamente a Ios artículos, obras e intervenciones legislativas de Bello que sí llevan su firma y que son indiscutiblemente de su cosecha. Se me decía que la situación sería idéntica a la que se podría producir si cuando se publicaran las obras completas de Kissinger se incluyeran en ellas los discursos que sobre política internacional pronuncia Ford o Nixon. $Y$ así los ejemplos podrían multiplicarse con más propiedad que el que nos señaló. Incluso en una "Antología de Discursos y Escritos de Andrés Bello", que ya citamos en párrafos anteriores, y que tiene 260 páginas; 150 de ellas la ocupan intervenciones de Joaquín Prieto y Manuel Bulnes. Error del anto-

"Diego Barros Arana: "Un decenio de la Historia de Chile", tomo I, Cap. IV, pp. 405-406. 
logista fue el no haber señalado las pruebas claras que sobre la paternidad de Bello en aquellos documentos oficiales menciona, con la seguridad de la certeza, Guillermo Feliú Gruz en su obra denominada: "Andrés Bello y la redacción de los documentos oficiales administrativos internacionales y legislativos de Chile"7. Con todo, con los trabajos "propios" de Bello hay suficientes elementos de juicio para dimensionar su preocupación por América Latina.

\section{El PROBLEMA de LA CONTINUIDAD}

Producido el hecho político de la Independencia, la cual para Bello no conllevaba la adquisición de la libertad, éste muestra una primera actitud que no es fácil de comprender si no se tienen todos Ios elementos de juicio propios de su realidad personal. En junio de 1813, Bello hace una presentación a la Regencia de Es̉paña. donde le dice al Serenísimo Señor: "El suplicante puede alegar también en su favor la notoria moderación de sus opiniones y conducta, que aún llegaron a hacerle mirar desafecto a la causa de la revolución; y cita en su abono el testimonio de cuantas personas le hayan conocido en Caracas, de los cuales no será difícil se encuentren muchos en Cádiz. En último, el suplicante hace presente a V. A. que no ha ejercido empleo ni comisión alguna bajo el Gobierno de Garacas desde la Declaración de la Independencia". El texto de esta presentación puede llamar a escándalo y ser causa de algunos adjetivos peyorativos que se le han propinado a Bello. Debe analizarse, por lo demás, a la luz de circunstancias muy especiales como son su precaria situación en Londres, la realidad incierta de Venezuela y su legítima pretensión de ser amnistiado "para regresar a cualquiera parte de los dominios de V. A. M. o a las que V. A. tenga por conducente"s.

Prescindiendo de la actitud que adoptara Andrés Bello a raíz de la emancipación de Venezuela y que bien pudo ser primordialmente motivada por las circunstancias especialísimas de aquel país, el problema de la continuidad, que es el que nos preocupa, lo vemos reflejado en el siguiente párrafo: "Una conquista impone cierta forma de gobierno al pueblo conquistado, y esta forma de gobierno influye luego sobre las costumbres del pueblo. Una Constitución Política sale del corazón de un partido o de la cabeza de un hombre; y si ella está construida con algún acierto, si no ha sido inspirada por falsas teorías, si consulta los intereses de la comuni-

TObra de la Biblioteca de los Tribunales del Distrito Federal. Fundación Rojas Astudillo, Caracas, Venezuela. 1957.

"Citado por Guillermo Feliú en la obra mencionada, p. 39. Esta "solicitud" ha sido comentada por Briceño Iragorry en un artfculo reproducido en la Revista Ghilena de Historia y Geograffa, Santiago de Ghile, julio-diciembre de 1954, No 122, pp. 64-69. 
dad, podrá influir sobre toda ella, modificar sus sentimientos, sus costumbres y representarla verdaderamente algún día". Continúa citando a Duvergier y Faudet, y afirma: "es necesario conocer el origen de éstas, las modificaciones sucesivas que han experimentado, y tener noticias exactas sobre las costumbres, Ios usos, los hábitos y el carácter nacional de cada pueblo"g.

Es perfectamente lógico extencler estos "requisitos de autenticidad", que Bello le exigia a las Constituciones, a todas las otras manifestaciones del intelecto que podrían haber configurado un adecuado "proyecto civilizador" para América Latina.

Son pocos los prohombres de la primera generación intelectual de América Latina que piensan en tales términos de autenticidad. En Brasil, siempre inclinado al pragmatismo, Fray Joaquín do Amon Caneça, en 1824, señalaba que:

"Sólo hay un partido, que es el de la libertad civil y de la felicidad: del pueblo, y todo lo que se aparte de esto debe ser rechazado enérgicamente... Brasil no es Europa, su clima, su posición geográfica, la extensión de su territorio, el carácter moral de su pueblo, sus costumbres y todas las demás circunstancias deben influir en el futuro de su Constitución ... nuestra Constitución ha.de ser brasileña en cuerpo y espíritu ... no queremos para el Brasil una Constitución adaptada al espíritu político de Europa"10.

A su vez, en Argentina, Juan Bautista Alberdi, que nació en 1810, el mismo año que Bello se dirigía a Londres, y con el cual tiene un parentesco espiritual más o menos claro, decía en su famoso "Fragmento preliminar del estudio del derecho": "Y bien: como primer principio, la filosofía manda al pueblo argentino ser él mismo; continuar la vida comenzada en Mayo, no repitiendo lo que se ve hacer en Francia o en Estados Unidos, sino conforme a lo que manda hacer la doble ley de la edad y del suelo. Más valioso y eficaz que copiar civilizaciones extranjeras, por adelantadas que parezcan, es adquirir una civilización propia, por imperfecta que sea. Por lo demás, -añadía Alberdi- no hay más perfección que la oportunidad"11.

Puede señalarse, con razón, que ya Alberdi no es de la primera generación de pensadores latinoamericanos. El propio intelectual tucumano lo reconoce así cuando nos aclara qué es papel de la nue-

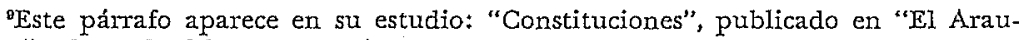
cano", el 11 de febrero de 1848.

${ }^{10}$ Citado por José Honorio Rodríguez, "Conciliaçăo e reforma no Brasil", p. 39. Editora Civilizaçăo Brasilera S. A., Río de Janeiro, 1965.

11Ramón Méndez Acebal: "Alberdi, el predestinado". Ediciones Plus Ultra, Talleres Gráficos Edili. Buenos Aires, 1979. p. 137.
} 
va generación procurar la base inteligente de que estaba provista la obra legada por el pasado.

Es importante recordar el pensamiento de Bello acerca del momento histórico en que se produjo la emancipación hispanoamericana, ya que bien puede pensarse que en otra oportunidad, habrían sido menos caóticas las consecuencias. Al respecto, Bello es categórico: "Estábamos en la alternativa de aprovechar la primera oportunidad, o de prolongar nuestra servidumbre de siglos. Si no habíamos recibido la educación que predispone para el goce de la libertad, no debíamos ya esperarla de España; debíamos educarnos a nosotros mismos, por costoso que fuese el ensayo; debía ponerse fin a una tutela de tres siglos, que no había podido preparar en tanto tiempo la emancipación de un gran pueblo".

Pero, ¿cuál era realmente el pensamiento de Bello acerca de las estructuras coloniales? ¿Qué se podía mantener de ellas? Si toda evolución histórica está compuesta de una "herencia" y de un "proyecto", ¿qué opinaba Bello de la primerà?

En un artículo suyo aparecido en "El Repertorio Americano", Bello censura las opiniones de Martín Fernández de Navarrete, autor de una "Colección de Viajes y Descubrimientos", muy leída en su época, en los siguientes términos:

"El candor con que el señor Navarrete ensalza las benévolas intenciones de los reyes y las sabias y bien entendidas disposiciones del Gódigo de Indias, no puede producir otro efecto en nosotros que de hacernos compadecer a los que piensan que puede ser prácticamente útil y benéfico un cuerpo de leyes cuya ejecución tiene como única garantía la autoridad de los jefes y jueces absolutos. Hayan sido en buena hora, piadosísimas las intenciones del legislador. Pero, ¿se han cumplido? ¿Y de qué sirven reglamentos que pueden quebrantarse o eludirse con impunidad

"La primera cualidad de una legislación, y sin la cual todas las otras son vanas, es la de hacerse observar. La parte más sabia y mejor observada de estas leyes, según sus panegiristas, es aquella que consulta los intereses de la metrópoli, no los nuestros, y es la que tiene por objeto la protección de los indígenas. ¿Y a qué se reduce? A mantenerlos en pupilaje perpetuo. Admirable legislación que niega al hombre el uso de sus derechos para precaver el abusol"12.

Al aparecer un artículo en la Revista Extranjera de Londres (noviembre 1837), criticando el reconocimiento por Estados Unidos de la República del Perú, por no haber dado prueba de la capacidad para gobernarse a sí mismo, Bello escribe en "El Araucano":

${ }^{12} \mathrm{E}$ I Repertorio Americano. Obras Completas de Andrés Bello. Caracas, 1952. 
"Toda esta filosofía moral y política presupone una de dos cosas, o que los suramericanos han sido condenados por el cielo a un pupilaje eterno, o que hubieran sido más capaces de gobernarse a sí mismos continuando otro siglo en la peior de todas las escuelas en las que un pueblo ha podido hacer el aprendizaje de la existencia política"18.

La verdad es que la última frase no ha dejado de llamarnos la atención en un hombre tan intrínsecamente prudente.

En su "Modo de escribir la historia", Bello muestra clara preferencia en favor de la narración de los hechos más que en la investigación de sus causas. De allí que lamentablemente no entrara en las consideraciones necesarias para desentrañar las razones últimas de lo que denomina "servidumbre colonial".

En todo caso, aquella "servidumbre" no fue capaz de llegar al "envilecimiento", penumbra desde la cual se vuelven irreversibles los fenómenos políticos. Está claro que el "genio de la raza" fue capaz eritonces de dominar el "peso de la noche". En la obra recién citada señala al efecto que:

"Hablamos de los hechos, como son en sí, y no pretendemos investigar las causas. Que el despotismo envilece y desmoraliza, es para nosotros un dogma; y si él no ha bastado ni en Europa ni en América para bastardear la raza, para aflojar en tres siglos el resorte de los sentimientos generosos -porque sin ellos no podrían explicarse los fenómenos morales de la España y de la América EspañoIa de nuestros días- preciso es que hayan coexistido causas que contrarrestan aquella perniciosa influencia"14.

Ahora bien, para "contrarrestar aquella perniciosa influencia", Bello hace extensiro a todo el "proyecto civilizador" las advertencias que formulara a raíz del valor de las constituciones. La búsqueda de la autenticidad hispanoamericana debía alejarse, tanto de los propósitos de un continuismo colonial como de un mero remedo europeo, sin por ello caer en un "ensimismamiento" estéril. Es una anticipación a la famosa prédica de Ortega y Gasset con cincuenta años de ventaja para Bello.

"Suponer-dice éste- que se quiere que cerremos los ojos a la luz que nos viene de Europa, es pura declamación. Nadie ha pensado en eso. Lo que se quiere es que abramos bien los ojos a ella, y que no imaginemos encontrar en ella lo que no hay ni puede haber"15.

${ }^{13} \mathrm{El}$ Araucano No 337, il de noviembre de 1837, 00.cc. de Andrés Bello. Caracas, 1952. El subrayado es nuestro.

${ }^{14}$ Op. Cit. p. 169.

${ }_{20}$ "Modo de escribir la historia". 'El Araucano, Ne 913, 4 de febrero de 1848. oo.cc. ya citadas. 
En el mismo trabajo añade unos párrafos decisivos:

"Nuestra cirilización será también juzgada por sus obras; y si se la ve copiar servilmente a la europea, aún en lo que ésta no tiene de aplicable, ¿cuál será el juicio que se formará de nosotros, un Michelet, un Guizot? Dirán: la América no ha sacudido aún sus cadenas; se arrastra sobre nuestras huellas con los ojos vendados; no respira en sus obras un pensamiento propio, nada original, nada característico, remeda las formas de nuestras filosofías, y no se apropia su espíritu. Su civilización es una planta exótica que no ha chupado todavía sus jugos a la tierra que la sostiene".

No deja de resultar paradojal que a raíz de una defensa categórica de la búsqueda de la autenticidad, muestre Bello un temor reverencial manifiesto por los juicios de Michelet o de Guizot. ¿Se trata acaso de contar con la aprobación de otros pentífices europeos? En todo caso, los dogmas de aquéllos parecen más positivos, aun cuando la paradoja subsiste. Este hecho nos recuerda el empeño que ponen algunos "nacionalistas" en citar frases y experiencias de otros nacionalistas de otras nacionalidades. ¿En qué quedamos?

Pero lo importante en estas líneas; que sólo pretenden hurgar la idea de la continuidad histórica en el pensamiento de Bello como elemento importante de un proyecto civilizador, es que éste reconoce, pese a sus reticencias iniciales, y de una manera categórica, la madurez de nuestros pueblos para concebirse una convivencia organizada.

En un editorial de "El Araucano", de febrero de 1842, escribe:

"Que los estados americanos tienen en sí mismos los medios de establecer un orden, y de un modo sólido y permanente, apenas habrá ponerse en duda, en presencia de los ejemplos y brillantez de dos de estos estados que marchando por la misma senda, tropezando con iguales inconvenientes y sin recursos ajenos o extraordinarios, han llegado felizmente a establecer un sistema regular político y económico, que lleva a todas las apariencias de estabilidad y todos los gérmenes de adelantamientos"1"̈.

Han pasado exactamente 139 años de aquel editorial, y los estados americanos aludidos son Chile y Venezuela. EI comentario fue escrito a raíz de la victoria de Chacabuco.

\footnotetext{
${ }^{20}$ Aniversario de la victoria de. Chacabuco "E1 Araucano" No 599,11 de febrero de 1842. 00.cG. ya citadas.
} 


\section{EL PROBLEMIA DEL CAMBio}

En cuanto a las nuevas formas de gobierno, Bello reconoce el hecho que: "no existían elementos republicanos; la España no había podido crearlos; sus leyes daban sin duda a las almas una dirección enteramente contraria. Pero en el fondo de esas almas, había semillas de magnanimidad, de heroísmo; de activa y generosa independencia; y si las costumbres eran sencillas y modestas... algo más había en esas cualidades que la estúpida insensatez de la esclavitud"17.

En carta fechada en noviembre de 1821, descle Londres; y dirigida a su "amigo Mier", Bello ya había sostenido "que la monarquía (limitada por supuesto) es el gobierno único que nos conviene; $y$ que miro como particularmente desgraciados aquellos países que pór sus circunstancias no permiten pensar en esta especie de Gobierno" 18

No olvidemos que la tentación monárquica de los propios libertadores es un hecho claro de la historia latinoamericana. Bolívar pensó en un monarca europeo, y después en un Presidente vitalicio. San Martín, en una monarquía constitucional. Los conserva dores mexicanos le entregaron el Poder a Maximiliano. No son los únicos casos. Se ha dicho que Lord Cochrane pensó en rescatar a Napoleón. Iturbide, desde el Perú, proponía un príncipe de la rama borbónica española. Hay obras históricas reputadas sobre "el carlotismo" de esta región. El propio Rosas, según cuenta Alberdi: "no encontraba gobernante más apropiado para la República, que la. Princesa Alicia de. Inglaterra"19. Y eso Io pensaba Juan Manuel de Rosas en Londres en octubre de 1857, después de haber gobernado Argentina veinte años. Sólo O'Higgins y José Artigas se mantuvieron irreductiblemente republicanos. No así ni Mariano Moreno, ni. Rivadavia, que lo fueron en un principio. Brasil, por su. parte, se transformó en Corte portuguesa desde 1808 hasta 1821. EI 7 de septiembre de 1821 el Príncipe don Pedro lanzó el famoso Grito de Ipiranga, pronunciando el "Fico" (me quedo). EI 12 de octubre se le declaraba "Enmperador Constitucional". El propio Precursor Miranda concebia una forma de gobierno para nuestros paises que tenía, según Salvador de Madariaga: "cabeza inca, cuerpo inglés y patas y cola de Castilla".

${ }^{27}$ Bello: "Investigaciones sobre la influencia de la conquista $y$ del sistema colonial de lơs españoles en Chile": oo.cc. ya citadas.

${ }^{18} \mathrm{Carta}$ incluida en la op. cit. de Feliú Cruz, p. 36.

${ }^{10}$ Escritos póstumos de Alberdi, Tol. I. p. 577, Vol. 16, p. 524. Acaba de aparecer en Buenos Aires (diciembre 19S0)/, una recopilación de cartas inéditas de Rosas y Roxas y Patrón, donde el primero postula una "Monarquía Republicana". El autor de là recopilación es el historiador José Read. Editorial Platero, Buenos Aires, 1980. 
No es la oportunidad de enumerar los múltiples casos de "libertadores" que se transfiguran en "dictadores". Eil "vacío de poder" nunca ha sido una cuestión desdeñable en América Latina. Otras figuras, como García Moreno, en el Ecuador, tratan de emular directamente a Felipe II.

Juan Bautista Alberdi, dice en sus "Bases", después de descartar la República ("no estamos maduros para ello") y la monarquía ("ya es imposible pensar en ella") lo siguiente: "Esa solución tiene un precedente feliz en la República Sudamericana, y es el que debemos a la sensatez del pueblo chileno, que ha encontrado en la energía del poder del Presidente las garantías públicas que la monarquía ofrece al orden y a la paz sin faltar a la naturaleza del gobierno republicano"20.

Otros, en cambio, estimaban que la fórmula feliz ya estaba dada por la Constitución norteamericana que, a la fecha, era un edificio en construcción, cuyos planos les eran desconocidos.

Ya hemos descrito la opinión de Bello sobre la validez de las constituciones: "si ella está construida con algún acierto, si no ha sido inspirada por falsas teorías, si consulta los intereses de la comunidad, podrá influir sobre toda ella, modificar sus sentimientos, sus costumbres y representarla verdaderamente algún día".

Está claro que Bello no volvió a háblar de la monarquía como su forma predilecta de gobierno, y una vez consustanciado con la realidad chilena se identificó como uno de los pilares fundamentales de la República. En cuanto al otro tema que dividió tan desgarradoramente a la región latinoamericana entre "unitarios" y "federalistas", no conocemos ninguna documentación que nos demuestre, de una manera generalizada para Latinoamérica, la inclinación de Bello por uno u otro sistema. En relación at caso concreto de Chile, Bello aparece identificado con la Constitución de $1833^{21}$.

Andrés Bello resulta particularmente categórico en condenar la tendencia latinoamericana a precipitarse en formas despóticas de gobierno. En un escrito que redactara en Londres y que refleja, precisamente, su inquietud por los disturbios de América, podemos leer los siguientes párrafos reveladores: "He oído decir a algunas personas que sería una fortuna para los americanos en su actual estado que algún individuo, por cualquier medio, asumiese un poder despótico sobre ellos".

Después de probar que esos mismos disturbios no pueden tener

${ }^{20}$ Alberdi: "Bases". Buenos Aires, 1952, p. 65. Op. Cit.

${ }^{31}$ En el caso de la República Argentina, como sabemos, esta polarización poIf́tica entre unitarios y federalistas constituyó una disyuntiva dramática. Una descripción objetiva del fenómeno político aludido $\mathrm{y}$ sus proyecciones en lo que concierne a la formación del Estado argentino puede verse en Mariano Grondona: "La Argentina en el tiempo y en el mundo". Cap. Ir. Editorial Primera Plana. Buenos Aires, 1967. 
otro término que el establecimiento de la libertad, continúa razonando de la siguiente manera:

"Pero suponiendo que el despotismo, hablando en general, pudiese establecerse a viva fuerza, no dudo en sostener, que nunca sucedería en países situados como la América del Sur, poblados de vastas montañas y sin caminos convenientes, $u$ otros medios de fácil comunicación. Si algún hombre pretendiese tiranizarlos, o aún influir en sus consejos contra el consentimiento de aquellos habitantes, las rebeliones reventarian por todas partes y a inmensas distancias; se organizaría una guerra de partidarios; los mismos soldados del déspota tomarían parte con el pueblo; se le desertarían sin temor de ser aprehendidos. Esta opinión se ha confirmado por la experiencia. Ha solido acontecer que algunos de sus caudillos, sin aspirar al despotismo, pero creyendo equivocadamente que podían restaurar la tranquilidad por la fuerza, han adoptado algunas medidas que en otras naciones podían considerarse como arbitrarias o violentas, pero que en las circunstancias de éstas eran justificables, o al menos excusables. Estos caudillos poseían grande influencia y popularidad, tenían ejércitos a su disposición, y estaban a la cabeza de los gobiernos: habian hecho eminentes servicios a la causa de la libertad, y se habían distinguido por sus talentos y valor, y con todas esas ventajas sus empresas han fallado"22.

Para Andrés Bello estaba muy claro, hace más de siglo y medio, que cualquiera fuese el panorama de anarquía, de caudillismo, de impotencia que ofreciera un país de la región, las medidas correctivas a aplicar deberían desembocar en una solución de libertad. "'Se manifiesta bien claro -dice Bello más adelante- que la presente lucha debe necesariamente terminar con la consolidación de la libertad").

Condenado el despotismo, y supuesto el funcionamiento de una Constitución prudente, Andrés Bello se nos presenta claramente "evolucionista". Los planteamientos evolucionistas de Bello tienen raigambre filosófica conocida en toda la región latinoamericana. Vienen de Comte, quien, si no ejerció mayor influencia en el desarrollo político del área fue debido a esa circunstancia casi generalizada de disturbio que desarticulaba, necesariamente, una marcha ordenada hacia el progreso. O dicho de manera más propia: "el desarrollo del orden" 23 .

${ }^{22}$ Aun cuando este artículo fue escrito en Londres, apareció posteriormente en "El Araucano" No 42, 2 de julio de 1831. 00.cc. ya citadas.

${ }^{23}$ E1 credo de Augusto Comte aparece sintetizado en el escudo brasileño con su divisa de "Orden y Progreso". "Toda organización debiera empezar por las ideas, pasar a las costumbres e inundar las instituciones". 
En relación a la participación de Bello en la redacción de los Mensajes Presidenciales de los gobernantes chilenos, los historiadores están de acuerdo en señalar que era el redactor oficial de los mismos. En la Historia General de Chile, Barros Arana, al referirse al Mensaje del Vicepresidente de la República, leído ante el Congreso Nacional en agosto de 1829, dice: "Como hemos dicho en otras ocasiones, estos documentos exan escritos por don José Joaquín de Mora, como los subsiguientes hasta 1860, fueron arreglados por don Andrés Bello"24. De dichos documentos, entonces, es posible deducir claramente el ideario evolucionista de Bello:

"Evitar novedades violentas, perfeccionar nuestra Constitución por los medios que ella misma franquea, sin cortar la continuidad de la vida política, es el voto de los pueblos y la marcha que sin duda aconsejará la prudencia" (1831).

"Cada nueva Legislatura introducirá en ellas las correcciones que le recomienden sus predecesoras, y el cuerpo social, como el de cada individuo, tomará gradual, y por decirlo así, insensiblemente, las formas que correspondan a las circunstancias $y$ al desenvolvimiento progresivo de la vida interior, sin soluciones violentas de continuidad que desarmen la máquina y hagan cada vez más difícil y precaria su reconstrucción" (1841).

"Dirán algunos (se refiere a la tranquilidad y al progreso de Ghile en contraste con otros países de la región), que todo se debe a la espontánea evolución de elementos que no han sido creados por el gobierno; y yo les responderé qué la primera y casi única gloria de los gobiernos es remover los estorbos a esa evolución espontánea; y que la remoción de esos estorbos no puede obtenerse sin atinadas providencias, sin combinaciones difíciles, cuyos autores tienen que combatir a menudo con preocupaciones envejecidas, con exageradas teorías y con ráfagas de impopularidad, en las que no pocas veces zozobran" (184I).

En la última cita que hemos reproducido, y que está contenida en la exposición que el Presidente Prieto dirigiera a la nación chilena el último día de su Administración, aparte del principio positivista de la evolución, se perfila el papel del estado dentro de los moldes más clásicos del liberalismo de la época. La "evolución espontánea" a que se alude, no era, sin embargo, la doctrina económica postulada por el país de Adam Smith, que había obtenido fuertes rebajas arancelarias en los puertos de Buenos Aires, La Guaira y el Caribe. Con mayor razón en Brasil. Estados Unidos, por su parte, desarrollaba una política económica claramente "proteccionista" desde la perfección de la unión aduanera entre sus trece es-

${ }^{2}$ Op. cit. de Feliú Cruz, p. 171. 
tados (1787). El liberalismo en lo económico no debía necesariamente debilitar la acción de la autoridad en otros campos. Y es así como en la misma exposición mencionada leemos que:

"Habíase previsto en la de 1828 (se refiere a la Constitución de Mora) a las libertades privadas, pero no se había prevenido contingencias que en la infancia de los Estados requieren remedios extraordinarios; y en el deseo generoso de enfrenar los abusos de la autoridad, no se cuidó lo bastante de darle energía de acción indispensable para la estabilidad del orden público y para la expedita $y$ regular administración de los intereses comunes".

\section{BELLO Y LA INTEGRAGTóN REgIONAI}

En un estudio que hiciéramos en marzo de 1975 y que editara el Instituto de Estudios Internacionales de la Universidad de Chile ${ }^{25}$, señalábamos que el pensamiento integracionista de Andrés Bello se sustenta sobre ciertos elementos básicos:

- Respecto irrestricto a la soberanía nacional;

- Enfasis en el comercio como instrumento integrador.

- Búsqueda de una reciprocidad efectiva en los compromisos pactados;

- Recelo a la transferencia de soberanía (o cesión del ejercicio de ciertas competencias en órganos de carácter regional).

- Respeto al principio de la no intervención;

- Necesidad de pactar en los convenios una cláusula de privilegios regionales, no extensivos, que opere sólo en favor de las naciones hispanoamericanas;

- Búsqueda de una política externa común.

Tanto en los convenios bilaterales, como frente a los congresos regionales que podían ser fuente de ulteriores convenios multilaterales, Andrés Bello mantuvo una actitud intransigente en la defensa y promoción de los elementos mencionados.

Bello partía de la base que entre las "repúblicas hispanoamericanas, ramas de un mismo tronco, unidas estrechamente por la semejanza de sus instituciones y por su común interés, hay una alianza formada por la misma naturaleza" 26 .

Esa "comuridad natural" debía expresarse en "pactos solemnes que determinen las obligaciones que emanan de ella". Pactos solemnes que sirvan para "estrechar su amistad recíproca; favorecer

${ }^{25}$ Raymundo Barros Charlín: "Consideraciones, sobre la integración latinoamericana en el siglo $\mathrm{xIx}$, con particular referencia a la polftica de Chile". Serie de Publicaciones Especiales No 8, 1975.

${ }^{20}$ Andrés Bello: Tomos xxI y xxir. Ministerio de Educación. Comisión Editora de sus oo,ca. Caracas. Venezuela, 1969. 
naturalmente su comercio; darse las unas a las otras todos los auxilios posibles para su seguridad y bienestar".

Se lamentaba Bello que las repúblicas americanas no tuvieran conciencia plena de la necesidad de orientar sus políticas internacionales a crear, con preferencia, vínculos sólidos entre sí.

"Perseguimos bienes dudosos, como el salvaje corre a tocar el iris que despliega sus vistosos colores sobre el horizonte; y, entretanto, apenas damos un momento de atención a ventajas seguras, que podemos fácilmente efectuar, entendiéndonos amistosamente, $y$ arrastrando las controversias y desavenencias internacionales con un espíritu fraternal y conciliatorio. En esta omisión es en lo que hallamos motivos de queja"27.

$\mathrm{Si}$ observamos el pensamiento integracionista de Andrés Bello, comparado con el de nuestros libertadores, especialmente Bolívar, San Martín y Morazán, en Centroamérica, vemos que Bello ponía el énfasis, por vez primera, en los vínculos comerciales como instrumentos de unidad.

De los grandes diseños políticos volcados a la necesidad de estructurar "federaciones" y "confederaciones" subregionales, de la prédica de la urgencia de elaborar "planes de defensa general" entre nuestras repúblicas ${ }^{28}$, se pasa a la sugerencia más realista de intensificar las corrientes de comercio:

" (E1 comercio) ha hecho más para suavizar las relaciones internacionales que todas las otras cosas juntas; es calculador por esencia; y cuanto mejor calcule sus intereses materiales, tanto más patentemente los verá apoyados en el cultivo de la paz y la amistad"29.

El mexicano Plácido García Reynoso recuerda que el Virrey de la Nueva España, Conde de Revillagigedo, en agosto de 1793, había propuesto, lisa y llanamente, reducir los aranceles para el intercambio hispanoamericano y mantener derechos elevados para las importaciones procedentes de otros países, "a fin de fomentar el desarrollo de los virreinatos, capitanías generales y demás posesiones españolas en el continente americano"30.

Una medida de esa naturaleza hubiera podido alterar el curso de nuestra historia.

200.CG. citadas, Tomo x, p. 637.

${ }^{2}$ Uno de los primeros planes de esta naturaleza fue el propuesto por Juan Egaña en 1810. Su histórico "Plan de Defensa General" inclufa a toda América del Sur, México y a los Estados Unidos de América, y fue formulado trece años antes que el de Monroe $y$ doce años antes que el de Bolfvar.

${ }^{\infty}$ oo.cc. citadas, Tomo x, p. 642.

${ }^{\infty}$ Antuario Uruguayo de Derecho Internacional No IV (1965-1966), p. 71. 
Bello, en cambio, se muestra menos ambicioso en sus planteamientos, inclinándose por perfeccionar convenios entre dos o más países, y por aplicar el mecanismo de lo que después se conocería como "cláusula Bello".

Este recela de los convenios "inicialmente" multilaterales; al menos de aquellos de carácter propiamente regional, que comprendan a toda la comunidad de repúblicas latinoamericanas.

Daba tres razones para incinarse por la concertación de entendimientos. "sucesivos" entre los países de la región.

"Primero: las negociaciones privadas pueden conducirse sucesivamente entre los varios estados...

Segundo: los estados obran de muy diverso modo, según su situación recíproca y sus medios de ofensa y defensa. Por ejemplo; las Repúblicas de Chile, Bolivia, Buenos Aires y el Perú, forman un sistema particular...

Tercero: ¿qué multiplicidad de trámites no es menester para realizar aquel acuerdo (multilateral) y darle todas las sanciones le. gales y cuánto tiempo no habría de consumirse en ello?"31..

En el Tratado de Montevideo, suscrito en 1980, por los mismos países que constituían la ALALC, se postula la concertación de acuerdos de alcance parcial, donde no participan todos los países. Estos acuerdos deben sujetarse a un proceso de "multilateralización progresiva" 32 .

Un aporte importante de Andrés Bello, tendiente a configurar en la región un espacio económico privilegiado frente a las relaciones comerciales con países ajenos a ella, se manifiesta en la insistencia suya de que las repúblicas iberoamericanas no. Ie extiendan a naciones ajenas los beneficios y privilegios especiales que se otorguen entre sf.

Tanto los Estados Unidos de Norteamérica, como las potencias europeas querían, al suscribir convenios con nuestros países, que se les otorgara, automáticamente, los beneficios de todo orden pactados entre las repúblicas de la región.

Gronológicamente, nos parece eso sí, que el primer convenio latinoamericano que reserva tratamientos especialísimos no extensivos a países fuera del área, fue el suscrito entre México e Inglaterra. Gon ello, el Canciller mexicano de la época, Lucas Alamán, quiso contribuir "a la idea sublime de formar una liga compuesta con todos los estados americanos" 33 . Obviamente, Alamán incluía en aquella liga a su poderoso vecino del norte.

qVer Tomo $x$ oo.cG. citadas.

${ }^{32}$ Artículo 7 del Tratado de Montevideo, 1980.

${ }^{3}$ Artículo citado de García Reynoso en el Anuario Uruguayo. 
La "cláusula Bello" se pacta en todos los convenios internacionales suscritos por Chile hasta 1845.

Desde 1845 a 1896 se deja de estipular, en razón de Ia falta de reciprocidad manifestada por las otras naciones de la región. Se vuelve a contemplar desde 1896. En la Memoria del Ministerio de Relaciones Exteriores de Ghile del año 1898, se justifica, la reimplantación de la "cláusula Bello" en los siguientes términos:

"El Gobierno persevera con todo empeño en el plan que se tiene trazado desde hace tiempo, de crear entre los países de la Amé. rica Latina, relaciones comerciales que estimulen recíprocamente las fuerzas vivas de su suelo, abriendo mercados fáciles y remuneradores a sus producciones naturales y a los esfuerzos de sus nacientes industrias" 34 .

En el marco de la ALALC, la clásula de la nación más favorecida como instrumento promotor del intercambio regional tenía una dirección opuesta a la de la "cláusula Bello" y estaba concebida en los siguientes términos:

"Gualquier ventaja, favor, franquicia, inmunidad o privilegio que se aplique por una Parte 'Gontratante en relación con un producto originario de o destinado a cualquier otro país, será inmediata $\mathrm{e}$ incondicionalmente extendido del producto similar originario de o destinado al territorio de las demás Partes Contratantes" 35 .

Decíamos que las disposiciones de ALALG sobre la materia tenían una dirección opuesta a Ia "cláusula Bello", por cuanto ésta pretende "reservar exclusivamente para la región ciertos privilegios", y aquélla, "extender a los países miembros ventajas que se le otorguen a terceros estados" 36 .

Feliú Cruz, al mencionar los documentos de carácter internacional redactados por Bello, establece su participación entre 1833 y 1852 en la elaboración de todos los tratados suscritos con países de la región. Los primeros de los cuales fueron: con Colombia y Pe-

"Efectivamente se pactó la "Cláusula Bello", en tratados celebrados con Suiza (1897); Italia, (1898); Dinamarca (1899); Noruega (1927); Egipto (1930); Checoslovaquia (1930).

${ }^{35}$ Artículo 18 del Tratado de Montevideo. La nueva dimensión de la cláusula de la nación más favorecida en el marco de la Asociación Latinoamericana de Integración, puede apreciarse con la lectura de los artículos 25, 27 y 44 del Tratado de Montevideo 1980.

3øUn análisis exhaustivo sobre el tema: "América Latina y la cláusula de la nación más favorecida" puede verse en la obra de este nombre, editada por Francisco Orrego Vicuña, Ediciones Paulinas, Santiago de Chile, 1972, especialmente pp. 33 a 94. 
rú (1822 y 1823, respectivamente); con Argentina (1826); con México (183I), con Bolivia (1833), con Brasil (1838) ${ }^{\mathbf{3} 7}$.

Otro punto de interés, lo constituye la participación de Andrés Bello en la redacción de las notas concernientes a lo que se ha dado en llamar "congresos americanos".

AI respecto, Barros Arana en su obra "Un decenio de la Historia de Chile", dice lo siguiente:

"Corresponden a la redacción de Bello las notas referentes a los subsiguientes provectos de Congresos Americanos, en las que BeIlo expresó sus ideas, ora en favor de la reunión de estas asambleas, desde el punto de lo útil que resultaban ellas para un niayor conocimiento de estas repúblicas, ora en apoyo de sus puntos de vista en la contestación que dio a Juan de Dios Gañedo"38.

Las notas de Bello concernientes a los denominados Congresos Americanos datan de 1840, 1841, I844, 1847, 1848 y 1864. En síntesis, ¿cuál es el pensamiento de Andrés Bello sobre este tema?

“¿Congreso de Plenipotenciarios? Esta expresión significa, a mi parecer, una reunión de ministros que se juntan para celebrar uno o más tratados sobre materias dadas, y que, una vez discutidas y acordadas, producen todos sus efectos para lo venidero, cesando desde entonces en sus funciones y retirándose los vocales"39.

Bello encontraba en los congresos, así concebidos, un instrumento de gran utilidad para dialogar sobre algunas materias que consideraba prioritarias, como eran aquellas relativas al comercio, navegación, comunicaciones.

Tratándose de simples reuniones transitorias, que no generen obligaciones que comprometan las soberanías nacionales y que sirvan para abordar temas de cooperación regional en las áreas ya mencionadas, Bello las considera útiles, a pesar de su recelo en relación al perfeccionamiento de los acuerdos multilaterales. Ahora bien, si aquellas reuniones fueren fuente de creación de un organismo regional permanente, apto para concebir palíticas y generar un derecho comunitario, el criterio de Bello es muy distinto. Del beneplácito pasa al franco rechazo.

"Op. cit. de Feliú Cruz Capitulos vir y vir.

${ }^{3 s}$ Barros Arana: 0o.cc. Tomo I, Capitulo IV, pp. 430-481. Montaner Bello, por su parte, dice: "El modo de pensar del Gobierno chileno sobre el proyecto del Congreso Americano, puede verse en los artículos publicados en "El Araucano" de 1844 por don Andrés Bello". (Tomo x de las oo.cc. de Bello. Memoria de Relaciones Exteriores de I844).

${ }^{30}$ oo.cc. de Bello, Tomo xxi. 
"Otra cosa sería - dice Bello- si se"quisiese constituir un congreso permanente para dar una verdadera unidad a diversas nacionalidades, decidiéndose las cuestiones, no por unanimidad sino por mayoría dè sufragios. Greo que usted convendrá en que esto será formar una Federación. Ahora bien -añadía- ca qué gobierno sería permitido abrar contra la Constitución que le ha dado el ser, y que ha jurado transmitir ilesa y en toda su integridad al gobierno legítimo que le suceda? ¿No obraría contra sus más esenciales deberes, conspirando con otros gobiernos a establecer un orden de cosäs que estaría en abierta oposición con: las leyes fundamentales de su país?" 40 .

No cabe duda que la razón constitucional que invoca Bello, es un simple pretexto Iegal para justificar su criterio reacio a la creación de organismos regionales que en el lenguaje contemporáneo se conoce como "supranacionales". Las constituciones pueden modificarse, y Bello lo sabe muy bien. Se discute su participación en la modificación de la Constitución de 1828 , que dio origen a la de $1833^{41}$.

En todo caso, la realidad de los "porfiados hechos" le dará razón a Bello, ya que, lamentablemente, de tales Congresos Americanos no emanó ningún compromiso de cierta envergadura integracionista.

En la reunión de 1856 se suscribió un Tratado Continental, en Santiago de Chile, entre nuestro país, Ecuador y Perú, al cual adhirieron posteriormente Bolivia, Costa Rica, Honduras, México, Nicaragua y el Paraguay. Cuando nuestro Congreso Nacional, recién en junio de 1859 , estudiaba su aprobación, se produjeron graves dificultades entre dos de sus signatarios. El Presidente Montt le informaría entonces, al $\mathrm{H}$. Congreso:

"Veo con sentimiento prolongarse el desacuerdo que existe entre el Ecuador y el Perú. El interés común de todas las Repúblicas Hispanoamericanas de que se conserven entre ellas los estrechos vínculos de amistad a que las llama su origen, sus antecedentes y sus futuros destinos, me movieron a autorizar al Ministro Plenipotenciario de la República en Lima, para ofrecer su mediación en aquellas diferencias. Estos buenos oficios han sido ăcep$\operatorname{tados}^{\prime \prime 4}$.

${ }^{40}$ Oo.ca. citadas, Tomo xxr.

41José Joaquín Mora, que había llegado a Chile desde Argentina, a principios de 1828, y al cual se debe la Constitución aprobada ese año, de tendencia eminentemente liberal, culpa a Bello de la tendencia que estima "conservadora" de la Constitución de 1833. (Op. Cit. de José Vila Selam, p. 37).

${ }^{4}$ Chile no ratificó el Convenio aludido. Memoria del Ministerio de Relaciones Exteriores, 1859. 


\section{REFLEXIÓN FINAL}

Bello, el "sistemático y riguroso" sabio según Sábato; el hombre frente al cual "... no es dado enumerar fríamente los inmensos méritos y servicios, que, si pudiéramos recordarlos todos, dudaría la razón que en una sola vida, un solo hombre, pudiera saber tanto, hacer tanto y amar tanto"43; el venezolano que hizo decir a Bolívar: "Yo conozco la superioridad de este caraqueño contemporáneo mío: fue mi maestro cuando teníamos una misma edad y yo le amaba con respeto", murió en 1865.

Y América Latina, que tanto le preocupara; esa "comunidad natural" de repúblicas, aún no enhebra su integración de una manera categórica. Han pasado doscientos años del nacimiento de BeIlo, y los países de esta región muestran unos recelos mutuos, unos quebrantos en la voluntad colectiva de ser, que en verdad produce desazón en los espíritus.

Quizás no sea cierta aquella frase de Julián Marías, de que "el tiempo no vuelve ni tropieza". .. Sirvan estas líneas de modesto homenaje al venezolano que supo también ser de Chile y de América. 